\title{
HDlive and 4D Ultrasound in the Assessment of Fetal Facial Expressions
}

\author{
${ }^{1}$ Toshiyuki Hata, ${ }^{2}$ Kenji Kanenishi, ${ }^{3}$ Uiko Hanaoka, ${ }^{4}$ Genzo Marumo
}

\begin{abstract}
Four-dimensional (4D) sonographic assessment of fetal facial expressions is considered to reflect normal and abnormal fetal neurological developments, and may be an important clue to predict the fetal brain function and well-being before and after birth. HDlive is a new surface-rendering mode, which uses an adjustable light source that facilitates the ability to create lighting and shadowing effects, thereby increasing depth perception. This technique facilitates extraordinarily realistic imaging of the fetal face, making it almost impossible to differentiate between actual photographs and HDlive images. In this article, we discuss recent topics regarding fetal facial expressions assessed by 4D ultrasound and HDlive, focusing on mouthing, sucking, yawning, blinking, tongue expulsion, scowling (pain/distress), and smiling. Moreover, we consider possibility of the existence of fetal emotion or awareness.
\end{abstract}

Keywords: HDlive, Four-dimensional ultrasound, Fetal facial expression, Fetal emotion, Fetal awareness.

How to cite this article: Hata T, Kanenishi K, Hanaoka U, Marumo G. HDlive and 4D Ultrasound in the Assessment of Fetal Facial Expressions. Donald School J Ultrasound Obstet Gynecol 2015;9(1):44-50.

Source of support: Nil

Conflict of interest: None

\section{INTRODUCTION}

There have been numerous studies on four-dimensional (4D) ultrasound evaluation of fetal facial expressions in the second and third trimesters of pregnancy. ${ }^{1-12}$ Fetal facial expressions are evaluated to assess normal fetal brain and central nervous system functions. ${ }^{1,2}$ Kurjak et $\mathrm{al}^{13}$ developed the Kurjak antenatal neurological test (KANET) for evaluating the fetal neurological condition

\footnotetext{
${ }^{1}$ Professor and Chairman, ${ }^{2}$ Associate Professor

${ }^{3}$ Senior Assistant Professor, ${ }^{4}$ President

${ }^{1-3}$ Department of Perinatology and Gynecology, Kagawa University Graduate School of Medicine, Miki, Kagawa, Japan

${ }^{4}$ Department of Obstetrics and Gynecology, Marumo Ladies Clinic Tokyo, Japan

Corresponding Author: Toshiyuki Hata, Professor and Chairman Department of Perinatology and Gynecology, Kagawa University Graduate School of Medicine, 1750-1 Ikenobe, Miki, Kagawa 761-0793, Japan, Phone: +81-(0)87-891-2174, e-mail: toshi28@ med.kagawa-u.ac.jp
}

using 4D ultrasound, and the assessment of facial expressions is the most important part of this innovative test. The facial expressions observed using HDlive are also considered to reflect whether the neurologic development of the fetus is normal or abnormal. ${ }^{14}$ HDlive may assist in evaluation of the fetal brain function, and offer a potential advantage related to 4D ultrasound. ${ }^{15,16}$

The present paper describes recent topics in the field of fetal facial expressions assessed by 4D ultrasound and HDlive, and considers the possibility of the existence of fetal emotion or awareness.

\section{FETAL FACIAL DEVELOPMENT}

Facial movements are controlled by cranial nerves $\mathrm{V}$ and VII that appear at around 10 and 11 weeks. 'Although the innervations of well-formed facial muscles begin very early in gestation at about 8 weeks, and by 16 weeks, all of the muscles used in facial expressions are formed, it is only later, between the gestational ages of 24 to 36 weeks, that the deposition of facial adipose tissue gradually builds up'. ${ }^{3}$

The fetal facial anatomy can be identified using 4D ultrasound and HDlive at 12 to 13 weeks of gestation (Fig. 1). Various realistic fetal facial structures can be recognized in the second and third trimesters of pregnancy (Fig. 2).

\section{FETAL FACIAL EXPRESSIONS}

We focus on fetal mouthing, sucking, yawning, blinking, tongue expulsion, scowling (pain/distress) and smiling employing 4D ultrasound and HDlive.

\section{Mouthing Movement (Fig. 3) ${ }^{15}$}

Mouthing movement was the commonest facial expression at 20 to 34 weeks' gestation, and the frequency of mouthing was significantly higher than those of the other facial expressions during this period. ${ }^{12}$ Moreover, the frequency of mouthing movement remained unchanged at 20 to 34 weeks of gestation (Figs 4A to F). Yigiter and $\mathrm{Kavak}^{6}$ reported similar findings, whereby there was no significant change during the second and third trimesters in mouthing movement. According to Reissland et $\mathrm{al}^{9}$, there was a significant difference in mouth stretch frequencies, with mouth stretch being the most frequent at 24 weeks and least frequent at 36 weeks of gestation, whereas 


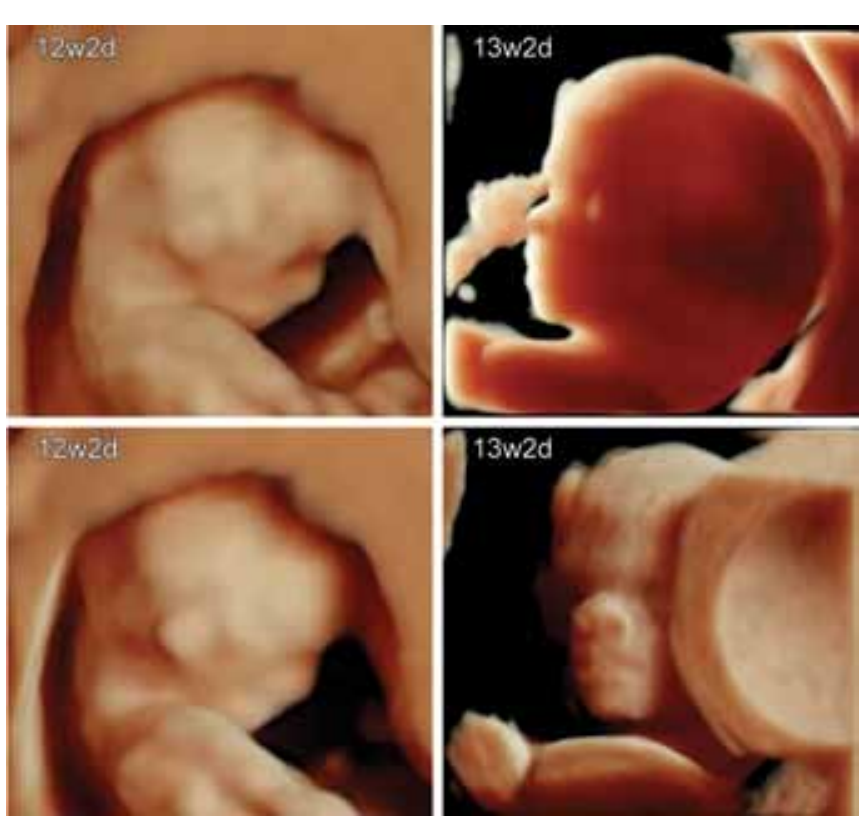

Fig. 1: HDlive images of normal fetuses at 12 to 13 weeks' gestation. The fetal facial anatomy can be clearly identified (Courtesy: Reprinted with permission from Hata T et al) ${ }^{15}$

the frequency of lip pucker did not differ significantly with the gestational age. Moreover, Reissland et $\mathrm{al}^{17}$ reported that the decline in neutral mouth movements and increase in lateralized mouth movements suggest the gradual establishment of fetal lateralized movements over time. There is evidence that fetuses show a bias toward leftward mouth movements when examining all lateralized mouth movements, suggesting that the 'expressive development' hypothesis is more strongly supported in their study.

\section{Sucking (Fig. 5)}

The frequency of sucking remains unchanged at 20 to 34 weeks' gestation (Fig. 6). ${ }^{6,12}$ Non-nutritive sucking is shown in diverse ways by fetuses who will mainly be born prematurely to facilitate nutritive sucking, and it can contribute to the management of an infant's feeding development. ${ }^{18}$ These findings suggest that a fetus may prepare for feeding after birth in the second half of pregnancy. ${ }^{12}$

\section{Yawning (Fig. 7)}

No changes in the frequency of fetal yawning between 20 and 36 weeks of gestation were found employing twodimensional ultrasound. ${ }^{19}$ Yigiter and Kavak ${ }^{6}$ demonstrated a gradual increase in the frequency of yawning between 20 and 34 weeks' gestation using $4 \mathrm{D}$ ultrasound, but there was no significant change. There was also a significant positive correlation between the frequency of fetal yawning and gestational age at 20 to 34 weeks of gestation (Fig. 8). ${ }^{12}$ However, Reissland et $\mathrm{al}^{8}$ showed a decline in the frequency of fetal yawning with age from 28 weeks' gestation. The recognition of fetal yawning
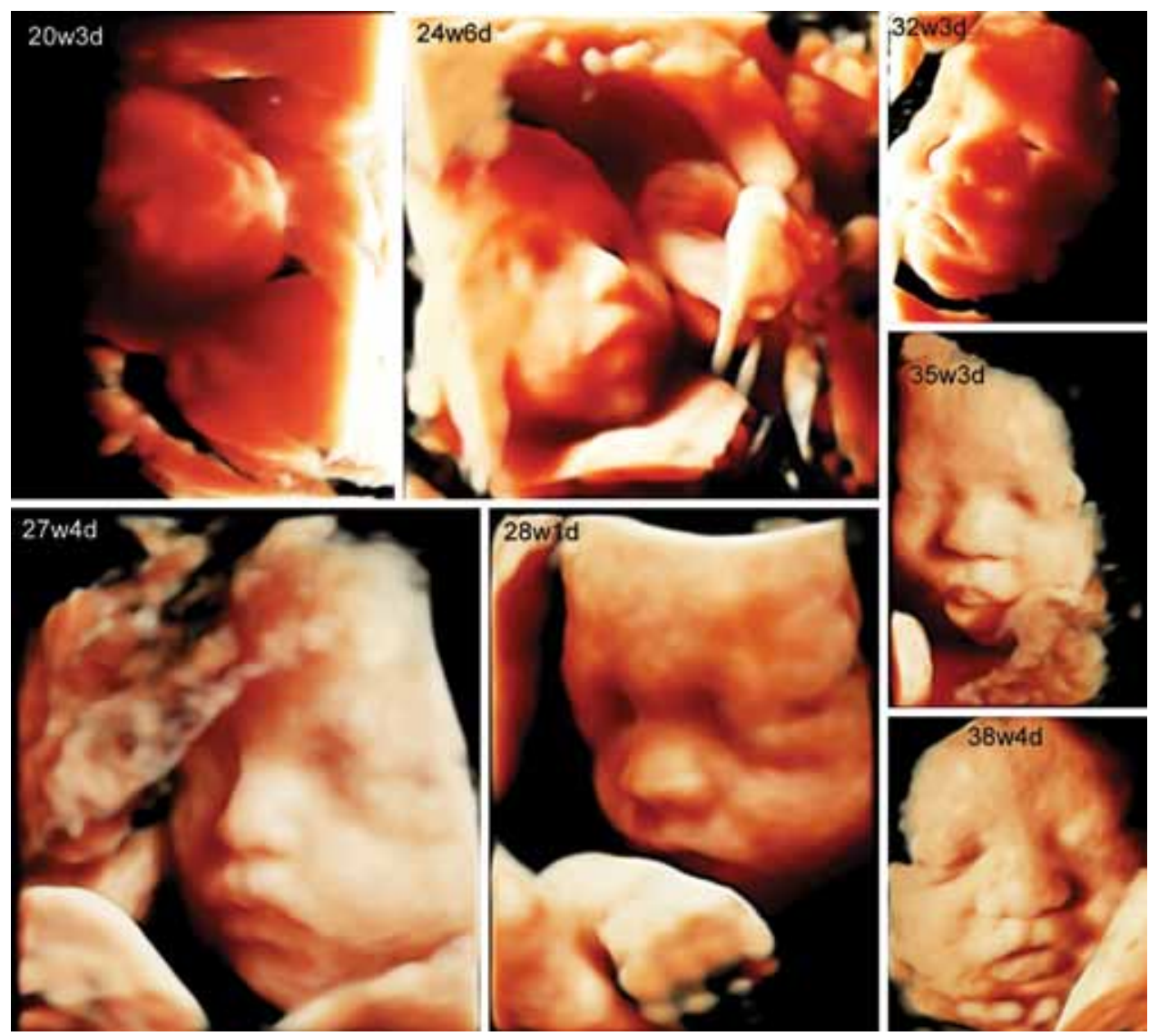

Fig. 2: HDlive images of various fetal faces in the second and third trimesters of pregnancy 


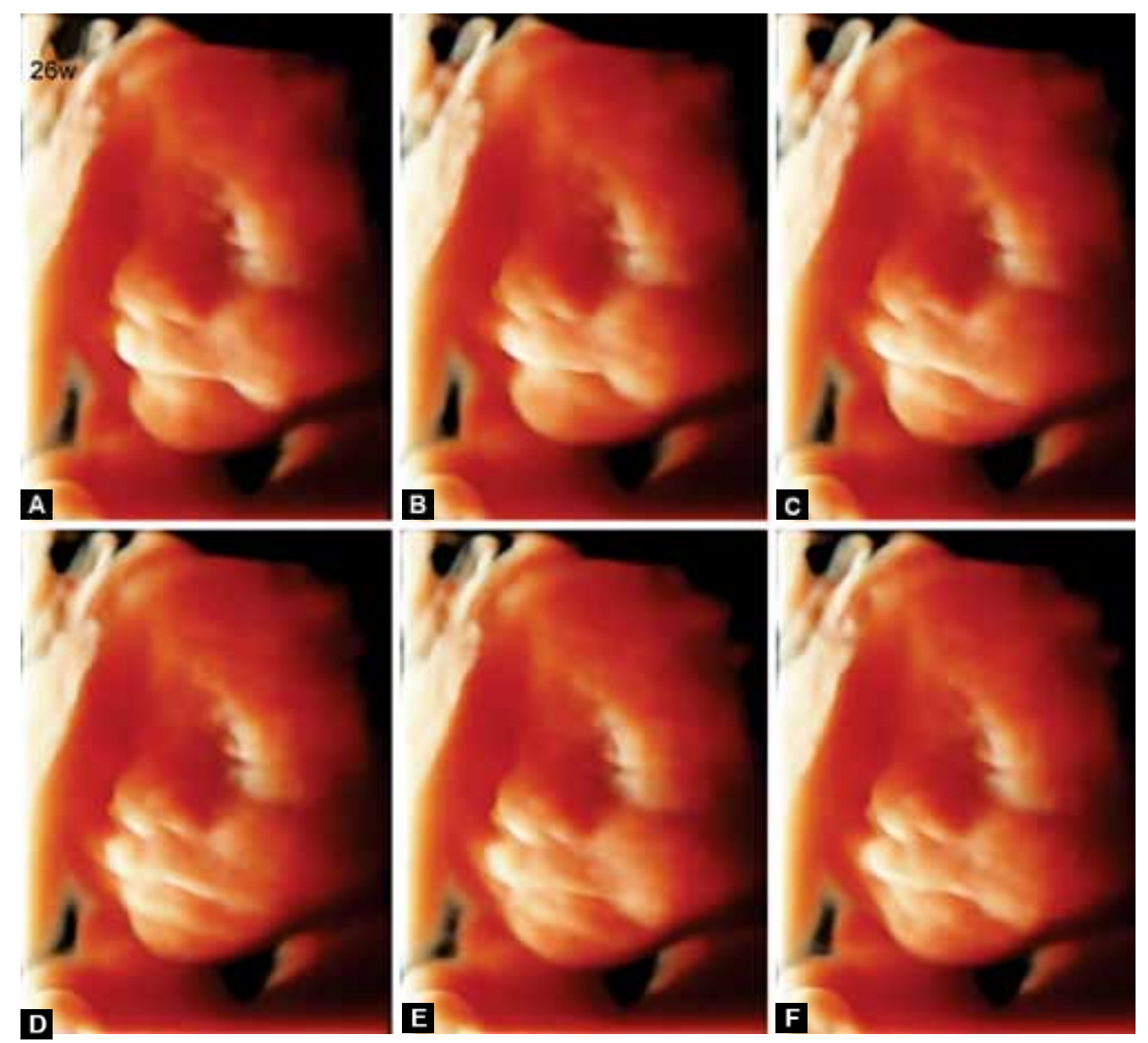

Figs 3A to F: Consecutive observations of fetal mouthing at 26 weeks of gestation (A to F). (Courtesy: Reprinted with permission from Hata T et al) ${ }^{16}$

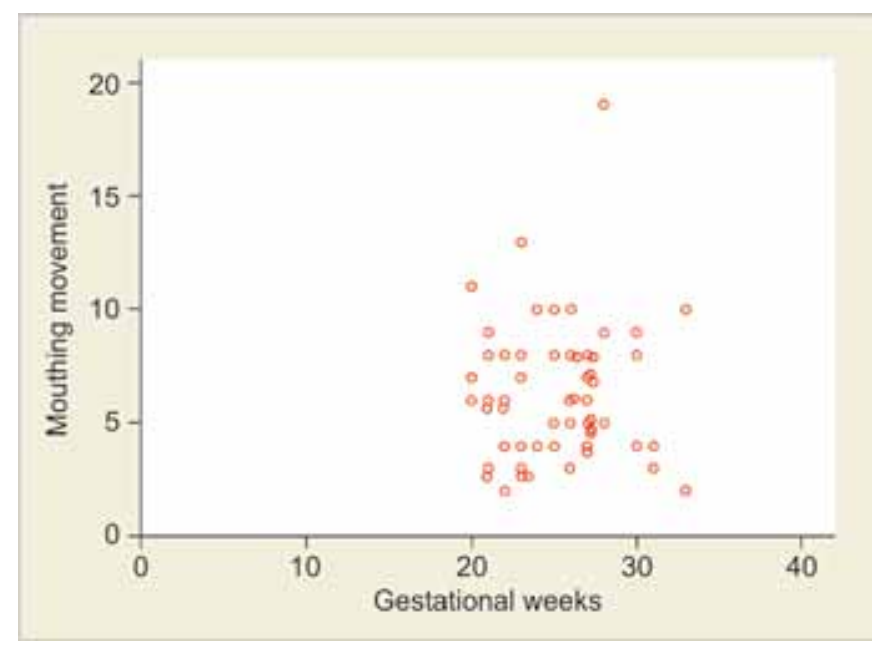

Fig. 4: Frequency of mouthing movement in relation to the gestational age. The frequencies of mouthing movement (median, 6; range, 1-19) were constant at 20 to 34 weeks

suggests healthy brainstem maturation, and will facilitate understanding of the neural underpinnings of sleep and arousal systems. ${ }^{20}$

\section{Blinking (Fig. 9)}

Kurjak et $\mathrm{al}^{5}$ reported that fetal blinking shows a peak frequency at around 28 weeks of gestation. However, its frequency increased with advancing gestational age during the second and third trimesters (Fig. 10). ${ }^{12}$

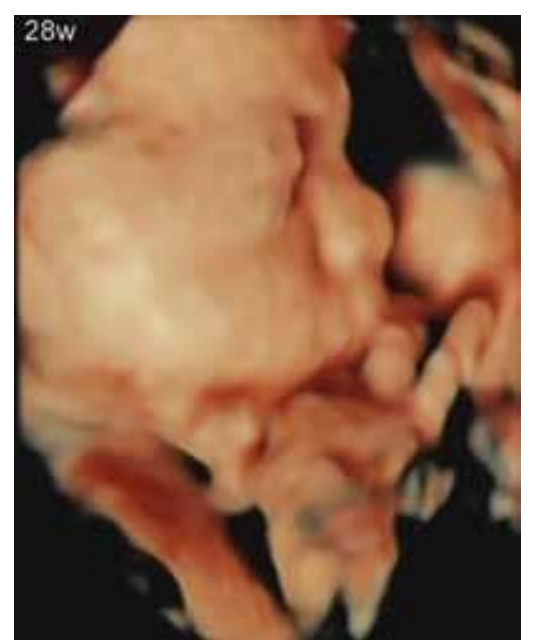

Fig. 5: HDlive image of fetal sucking at 28 weeks of gestation. The fetus sucks his/her fingers

\section{Tongue Expulsion (Fig. 11)}

The frequencies of tongue expulsion increased with advancing gestation (Fig. 12). ${ }^{12}$ Yigiter and $\mathrm{Kavak}^{6}$ also found a gradual increase in the frequency of tongue expulsion after 20 weeks of gestation. However, Kurjak et $\mathrm{al}^{5}$ reported that the frequency of tongue expulsion increases from 16 to 24 weeks of gestation, and remains unchanged after 24 weeks. 


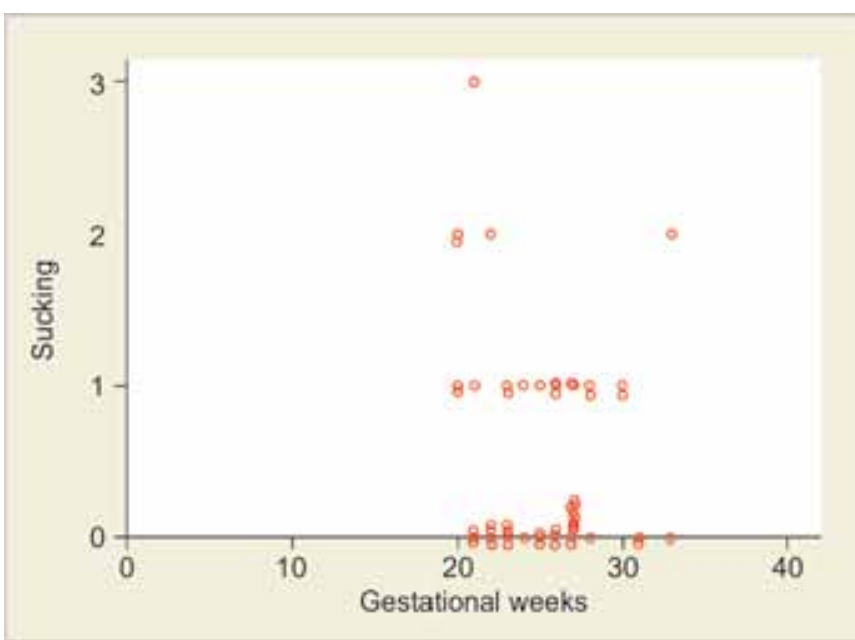

Fig. 6: Frequency of sucking in relation to the gestational age. The frequencies of sucking (median, 0; range, 0-3) were constant at 20 to 34 weeks

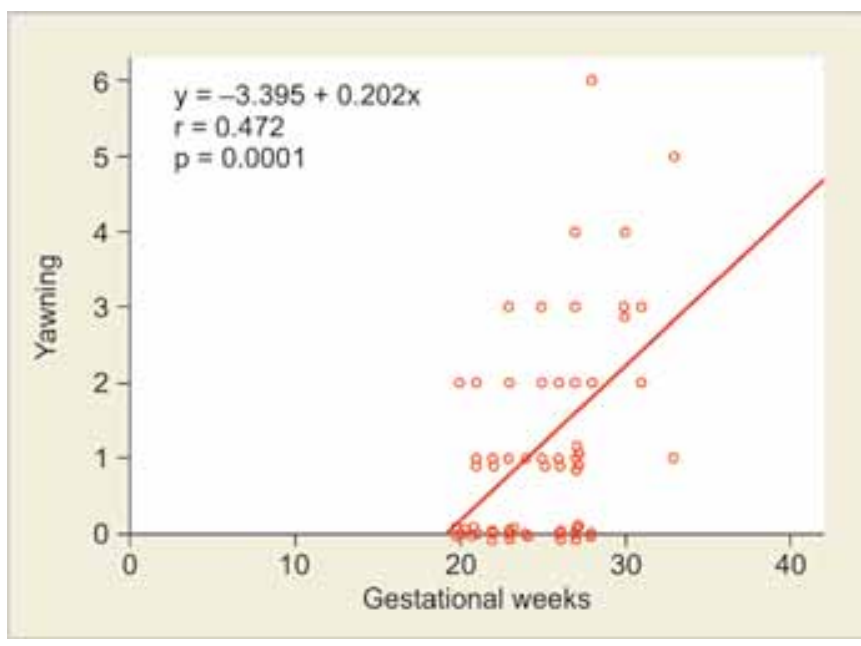

Fig. 8: Frequency of yawning in relation to the gestational age. (Courtesy: Reprinted with permission from Hata T et al) ${ }^{12}$

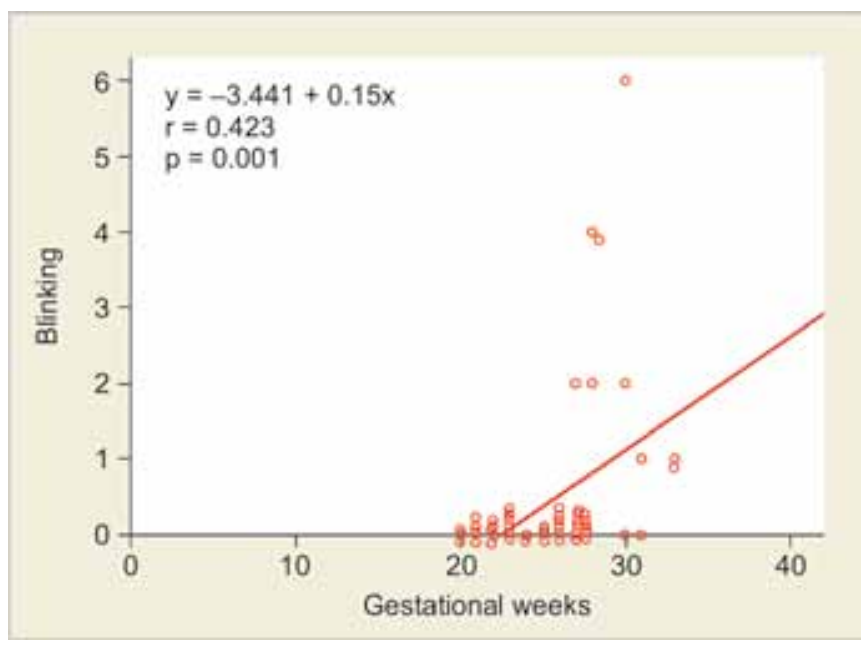

Fig. 10: Frequency of blinking in relation to the gestational age (Courtesy: Reprinted with permission from Hata T et al) ${ }^{12}$

\section{Scowling (Pain/Distress) (Figs 13 and 14)}

The frequency of scowling (pain/distress) increased with advancing gestation (Fig. 15). ${ }^{12}$ Previous investigations $s^{6,11}$ also showed similar findings. Reissland et $\mathrm{al}^{11}$ docu-

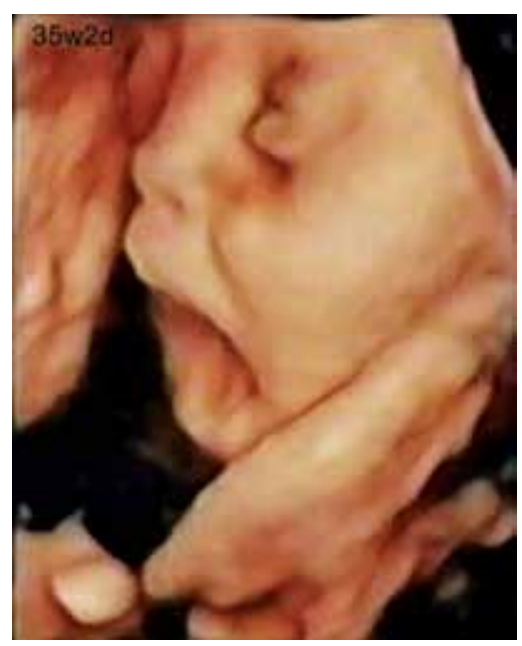

Fig. 7: HDlive image of fetal yawning at 35 weeks and 2 days of gestation

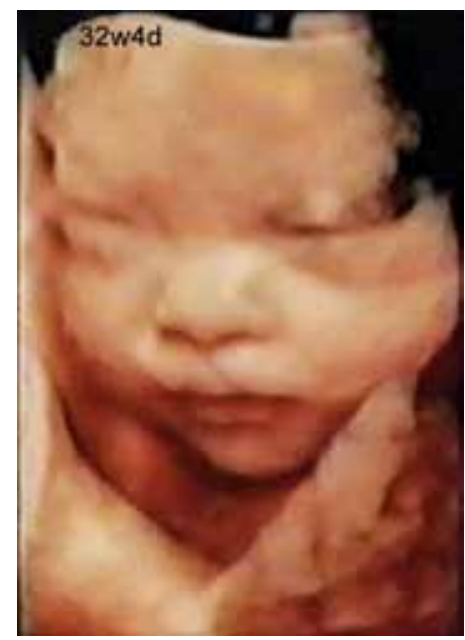

Fig. 9: HDlive image of fetal blinking at 32 weeks and 4 days of gestation

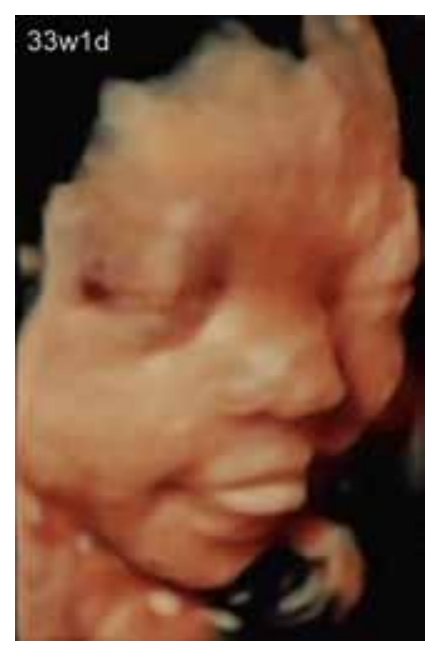

Fig. 11: HDlive image of fetal tongue expulsion at 33 weeks and 1 day of gestation

mented that healthy fetuses progress toward an increasingly complete pain/distress (scowling) expression as they mature. It is assumed that the fetus reacts to painful stimuli from 24 weeks' gestation, and that it may be possible that 


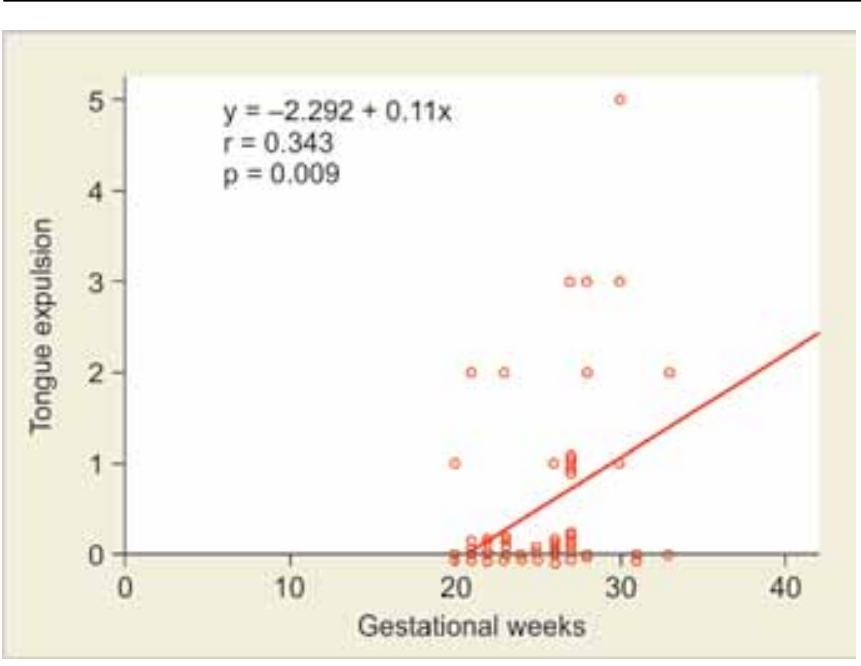

Fig. 12: Frequency of tongue expulsion in relation to the gestational age (Courtesy: Reprinted with permission from Hata T et al) ${ }^{12}$

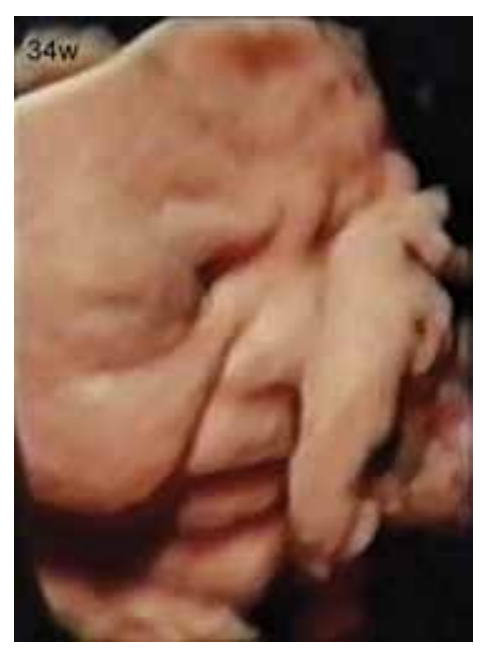

Fig. 14: HDlive image of fetal scowling at 34 weeks (pain/distress) of gestation

this occurs from 16 weeks of gestation. ${ }^{21,22}$ Facial expressions (fetal pain/distress) as important indicators of fetal pain may include several features, such as brow bulge, eye squeeze, nasolabial furrow and open mouth (Fig. 16). ${ }^{23}$ Other indicators of fetal pain are body movements, such as the activity of the arms and legs, clenching of the fists or toes, and sudden body movements. ${ }^{23}$ These findings suggest that the increasing frequency of fetal scowling (pain/distress) with advancing gestation may be an adaptive process, which is beneficial to the fetus after birth. ${ }^{11}$

\section{Smiling (Figs 17 and 18)}

Yigiter and $\mathrm{Kavak}^{6}$ found that fetal smiling expression shows a peak frequency between 24 and 32 weeks of gestation. In another study, the frequency of smiling increased with advancing gestation between 20 and 34 weeks (Fig. 19). ${ }^{12}$ The complexity of fetal facial movements

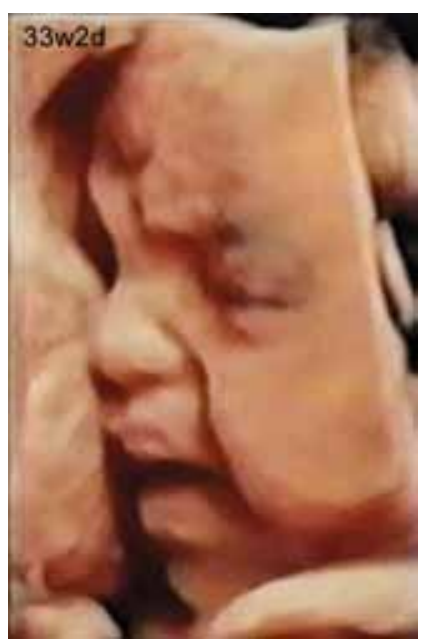

Fig. 13: HDlive image of fetal scowling (pain/disress) at 33 weeks and 2 days of gestation

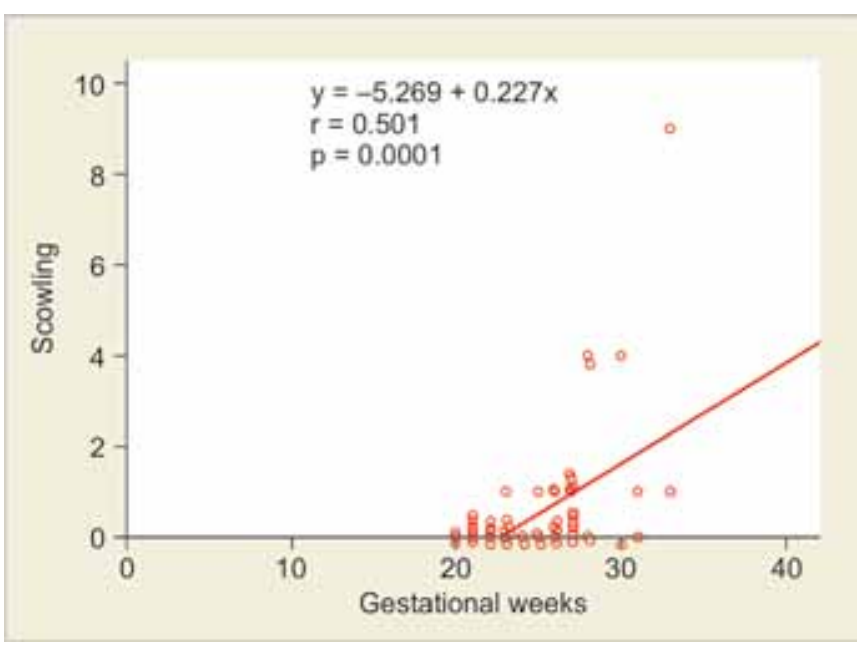

Fig. 15: Frequency of scowling in relation to the gestational age (Courtesy: Reprinted with permission from Hata T et al) ${ }^{12}$

such as laughter-face gestalt also increased with the gestational age. $^{3}$

\section{FETAL EMOTION-LIKE BEHAVIOR (FIGS 20 AND 21)}

The question raised here is whether or not facial emotionlike expressions or emotion-like behaviors represent a reliable behavior or emotional state, or simply constitute reflexive behavior on the part of the fetus. ${ }^{24}$ The answer to this question still remains unresolved. Myowa-Yamakoshi and Takeshita ${ }^{25}$ found that fetuses opened their mouths before their hands came in contact with them employing $4 \mathrm{D}$ ultrasound, and suggested the possibility that human fetuses perceive the manner in which they should move their hands to make contact with their mouths. Fetal facial expressions and emotion-like behaviors observed by HDlive and $4 \mathrm{D}$ ultrasound may represent some kinds of fetal emotion and awareness. Therefore, these facial emotion-like expressions or emotion-like behaviors may 


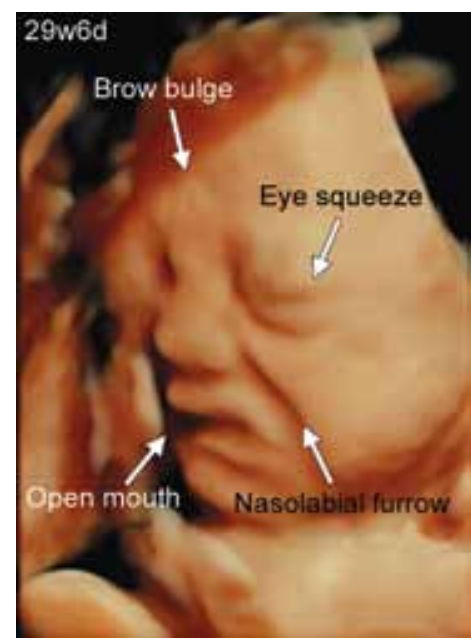

Fig. 16: HDlive image of fetal pain at 29 weeks and 6 days of gestation. Facial expressions as important indicators of fetal pain may include several features, such as brow bulge, eye squeeze, nasolabial furrow and open mouth

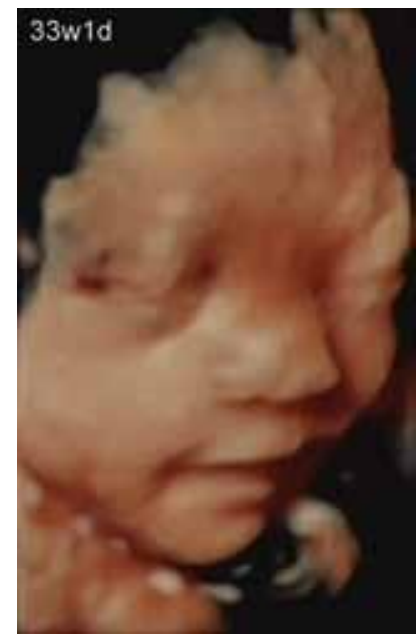

Fig. 18: HDlive image of fetal smiling at 33 weeks and 1 day of gestation

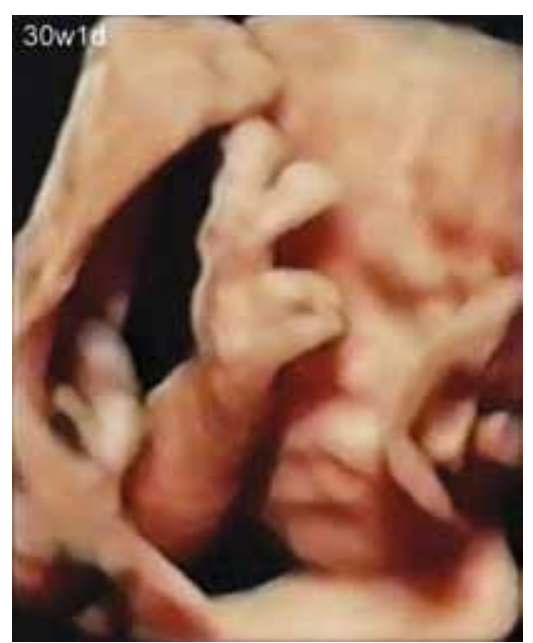

Fig. 20: HDlive image of a healthy fetus at 30 weeks and 1 day of gestation. This fetus is showing a peace sign using his/her fingers

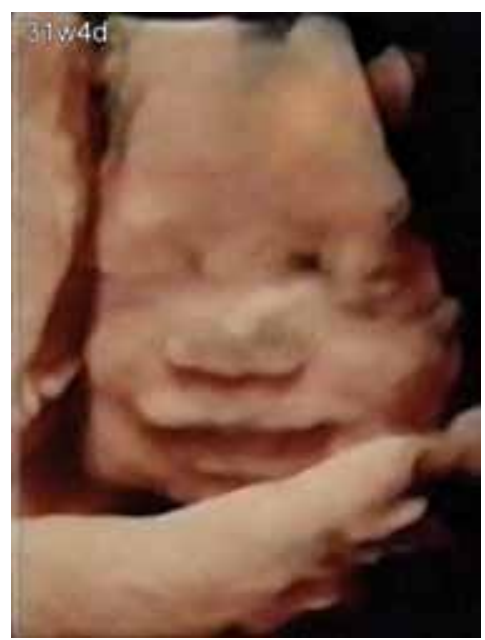

Fig. 17: HDlive image of fetal smiling at 31 weeks and 4 days of gestation

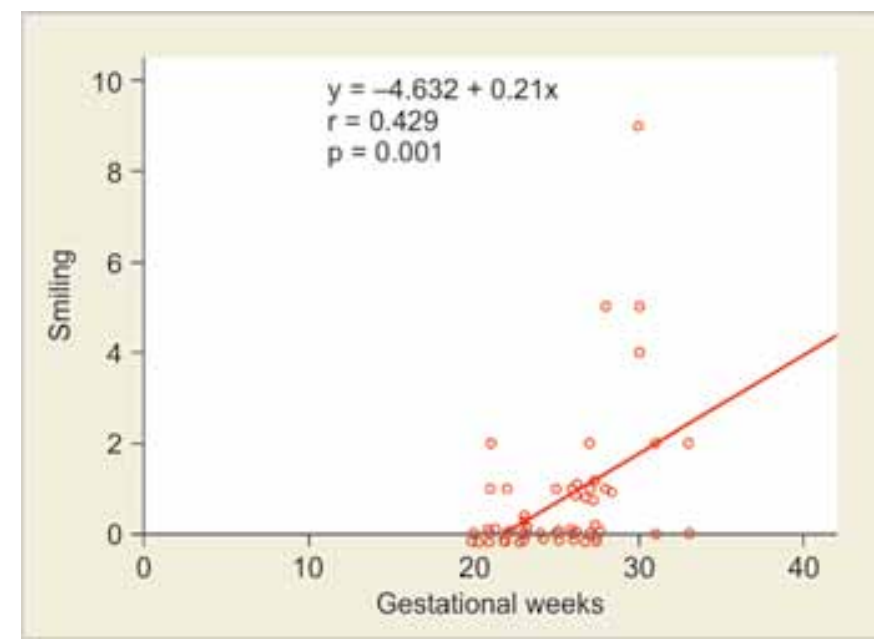

Fig. 19: Frequency of smiling in relation to the gestational age (Courtesy: Reprinted with permission from Hata T et al) ${ }^{12}$

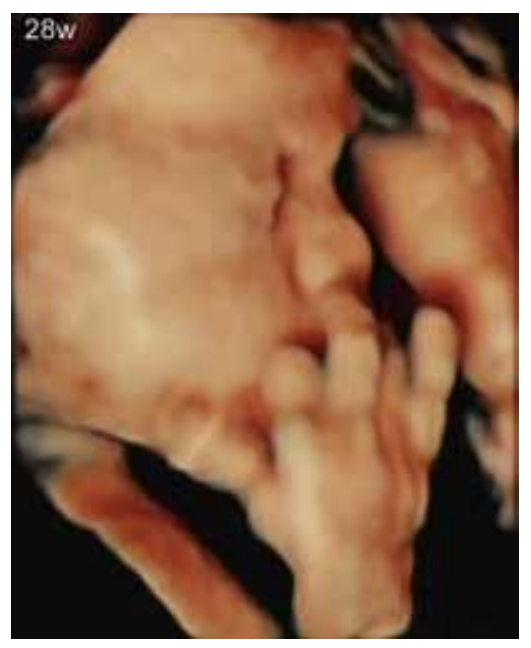

Fig. 21: HDlive image of a healthy fetus at 28 weeks of gestation. This fetus is picking his/her nose 
represent a reliable behavior or some emotional states of the fetus in utero. ${ }^{15}$ However, further studies using HDlive and 4D ultrasound are needed to obtain the evidence of fetal emotion or awareness.

\section{CONCLUSION}

'Increasing frequencies of more complicated facial expressions, such as smiling and scowling, with advancing gestation may indicate the development and maturation of the fetal brain and central nervous system. However, this technology does not provide specific information on which nervous centers are developed or undergoing development, and correlations of the described facial expressions and the fetal condition or even later neonatal neurodevelopment are not yet clear'. ${ }^{12}$ HDlive and 4D ultrasound assessments of fetal facial expressions are very interesting topics, and HDlive and $4 \mathrm{D}$ ultrasound may be an important modality in future fetal neurobehavioral research and in the evaluation of normal and abnormal fetal facial expressions.

\section{ACKNOWLEDGMENTS}

The work reported in this paper was supported by a Grant-in-Aid for Scientific Research on Innovative Areas 'Constructive Developmental Science' (No. 24119004), and a Research Grant (No. 25462561) from the Ministry of Education, Culture, Sports, Science and Technology, Japan.

\section{REFERENCES}

1. Yan F, Dai SY, Akther N, Kuno A, Yanagihara T, Hata T. Four-dimensional sonographic assessment of fetal facial expression early in the third trimester. Int J Gynecol Obstet 2006;94(2):108-113.

2. Kurjak A, Azumendi G, Andonotopo W, Salihagić-Kadić A. Three- and four-dimensional ultrasonography for the structural and functional evaluation of the fetal face. Am J Obstet Gynecol 2007;196(1):16-28.

3. Reissland N, Francis B, Mason J, Lincoln K. Do facial expressions develop before birth? PLoS ONE 2011;6(8):e24081.

4. Kurjak A, Stanojević M, Azumendi G, Carrera JM. The potential of four-dimensional (4D) ultrasonography in the assessment of fetal awareness. J Perinat Med 2005;33(1):46-53.

5. Kurjak A, Andonotopo W, Hafner T, Salihagić-Kadić A, Stanojević M, Azumendi G, Ahmed B, Carrera JM. Normal standards for fetal neurobehavioral developments longitudinal quantification by four-dimensional sonography. J Perinat Med 2006;34(1):56-65.

6. Yigiter AB, Kavak ZN. Normal standards of fetal behavior assessed by four-dimensional sonography. J Matern Fetal Neonatal Med 2006;19(11):707-721.

7. Lebit FD, Vladareanu R. The role of $4 \mathrm{D}$ ultrasound in the assessment of fetal behaviour. Medica (Buchar) 2011;6(2):120-127.
8. Reissland N, Francis B, Mason J. Development of fetal yawn compared with non-yawn mouth openings from 24-36 weeks gestation. PLoS ONE 2012;7(11):e50569.

9. Reissland N, Mason J, Schaal B, Lincoln K. Prenatal mouth movements: can we identify coordinated fetal mouth and lip actions necessary for feeding? Int J Pediatr 2012;2012:848596.

10. Kanenishi K, Hanaoka U, Noguchi J, Marumo G, Hata T. 4D ultrasound evaluation of fetal facial expressions during the latter stages of the second trimester. Int J Gynecol Obstet 2013;121(3):257-260.

11. Reissland N, Francis B, Mason J. Can healthy fetuses show facial expressions of 'pain' or 'distress'? PLoS ONE 2013;8(6): e65530.

12. Sato M, Kanenishi K, Hanaoka U, Noguchi J, Marumo G, Hata T. 4D ultrasound study of fetal facial expressions at 20-24 weeks of gestation. Int J Gynecol Obstet 2014;126(3):275-279.

13. Kurjak A, Miskovic B, Stanojević M, Amiel-Tison C, Ahmed B, Azumendi G, Vasilj O, Andonotopo W, Turudic T, SalihagicKadic A. New scoring system for fetal neurobehavior assessed by three- and four-dimensional sonography. J Perinat Med 2008;36(1):73-81.

14. Hata T, Hanaoka U, Mashima M, Ishimura M, Marumo G, Kanenishi K. Four-dimensional HDlive rendering image of fetal facial expression: a pictorial essay. J Med Ultrasonics 2013;40(4):437-441.

15. Hata T, Hanaoka U, Tenkumo C, Sato M, Tanaka H, Ishimura $M$. Three- and four-dimensional HDlive rendering images of normal and abnormal fetuses: pictorial essay. Arch Gynecol Obstet 2012;286(6):1431-1435.

16. Hata T, Kanenishi K, Hanaoka U, Uematsu R, Marumo G, Tanaka H. HDlive study of fetal development and behavior. Donald School J Ultrasound Obstet Gynecol 2014;8(3):250-265.

17. Reissland N, Francis B, Aydin E, Mason J, Exley K. Development of prenatal lateralization: evidence from fetal mouth movements. Physiol Behav 2014(May 28);131:160-163.

18. Harding C, Frank L, Dungu C, Colton N. The use of nonnutritive sucking to facilitate oral feeding in a term infant: a single case study. J Pediatr Nurs 2012;27(6):700-706.

19. Roodenburg PJ, Wladimiroff JW, van Es A, Prechtl HFR. Classification and quantitative aspects of fetal movements during the second half of normal pregnancy. Early Hum Dev 1991;25(1):19-35.

20. Walusinski O, Kurjak A, Andonotopo W, Azumendi G. Fetal yawning assessed by 3D and 4D sonography. Ultrasound Rev Obstet Gynecol 2005;5(3):210-217.

21. Van de Velde M, Jani J, De Buck F, Deprest J. Fetal pain perception and pain management. Semin Fetal Neonat M 2006;11(4):232-236.

22. Katarzyna KK, Miroslaw W. Is fetus able to feel pain? Ginekol Pol 2011;82(2):133-136.

23. Bellieni CV. Pain assessment in human fetus and infants. AAPS J 2012;14(3):456-461.

24. Hata T, Dai SY, Marumo G. Ultrasound for evaluation of fetal neurobehavioural development: from 2D to $4 \mathrm{D}$ ultrasound. Inf Child Dev 2010;19(1):99-118.

25. Myowa-Yamakoshi M, Takeshita H. Do human fetuses anticipate self-oriented actions? A study by four-dimensional (4D) ultrasonography. Infancy 2006;10(3):289-301. 